\title{
Hybrid approach for complicated Type B aortic dissection
}

\author{
Hybrydowe podejście do powikłanego rozwarstwienia aorty typu B
}

\author{
Omar Gomez-Monterrosas ${ }^{1}$, Giancarla Scalone², Paolo Tripodi ${ }^{1}$, Gaspar Mestres ${ }^{1}$, Vicente Riambau ${ }^{1}$ \\ 'Vascular Surgery Department, Thorax Institute, Hospital Clinic, Barcelona, Spain \\ ${ }^{2}$ Department of Cardiology, Catholic University of Sacred Heart, Rome, Italy
}

A 39-year-old male, smoker, with type I diabetes mellitus, hypertension, obesity, and dyslipidaemia arrived at our attention for tearing back pain. An angiographic computed tomography (angio-CT) showed full length aortic dissection from the origin of the left subclavian artery (LSA) to both iliac arteries. Optimal medical treatment was started with nitroprusside, alpha- and beta-blockers, angiotensin converting enzyme-inhibitors, and calcium receptor antagonists. The patient remained asymptomatic and with normal renal function until 15 days later, when he presented back and abdominal pain, intermittent claudication, and increased creatinine value. Angio-CT showed progression of dissection involving LSA origin (Fig. 1A, yellow arrow), significant compression of the true lumen of aorta (Fig. 1B, yellow arrow), and thoracic and lumbar aortic dissection (Fig. 1C, D). By centreline (Fig. 1E) we quantified the diameters of aortic arch (32 mm) (Fig. 1E, 1), proximal landing zone (28 mm) (Figs. 1E, 2), and true lumen at the point of maximum compression (13 mm) (Fig. 1E, 3). The patient was treated with carotid subclavian by-pass, thoracic endovascular repair (with Relay NBS PLUS $32 \times 32 \times 200 \mathrm{~mm}$ and $30 \times 26 \times 150 \mathrm{~mm}$ ), coil embolisation of LSA, and iliac stenting with covered stents $(12 \times 40 \mathrm{~mm}$ in right common iliac artery; $12 \times 60$ in right external iliac artery; $14 \times 40 \mathrm{~mm}$ and $14 \times 40 \mathrm{~mm}$ in left external iliac artery). Angio-CT performed 10 days later showed complete coverage of the primary tear site and complete occlusion of the LSA (Fig. 2A-D) and a good result of thoracic endovascular repair and iliac stenting (Fig. 2E-G). One week later the patient was discharged without complications. The hybrid approach is safe and feasible for complicated aortic Type B dissection. Case planning is critical for procedural success.



Figure 1. A-E. Images from angiographic computed tomography and centreline analysis before the intervention



Figure 2. A-G. Images from angiographic computed tomography acquired ten days after the intervention 